diversity, the largest population, and the most extensive tourism industry, has more at risk than any other state in the U.S." CEPR urged Congress to increase funding for research on exotic pests and to reexamine the role that APHIS plays in protecting U.S. agriculture from foreign invaders.

A major aim of CEPR over the next several years will be to help coordinate joint efforts by
USDA, CDFA, the agricultural industry and university researchers in fighting exotic pests that have been, or could be, introduced into the state. Other major problems on the horizon include the spread of rice blast, a fungal disease of rice in the Sacramento Valley and the arrival of destructive fire ants in Kern County almond orchards. - Cindy Giorgio

\title{
Silverleaf whitefly extends range
}

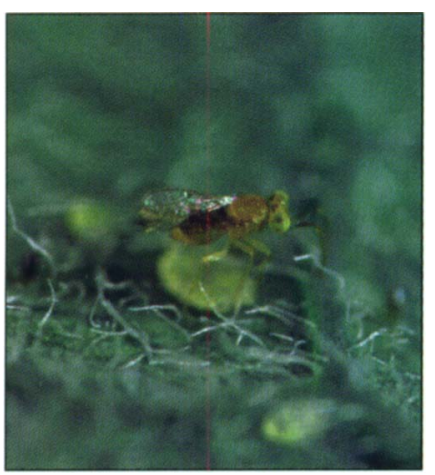

$\mathrm{T}$ he silverleaf whitefly has extended its range from the Imperial Valley into the San Joaquin Valley, where it has become a pest of cotton in areas where there is a high concentration of both cotton and citrus. "We have found silverleaf whitefly as far north as Merced County," says UC entomologist Charles Summers.

The agricultural commissioner's office in Imperial Valley reported a $\$ 111$ million crop loss in 1991-1992. Now that growers have adjusted to the pest, that kind of crop loss should not occur again, but the big cost is in pesticides. The melon crop probably uses the

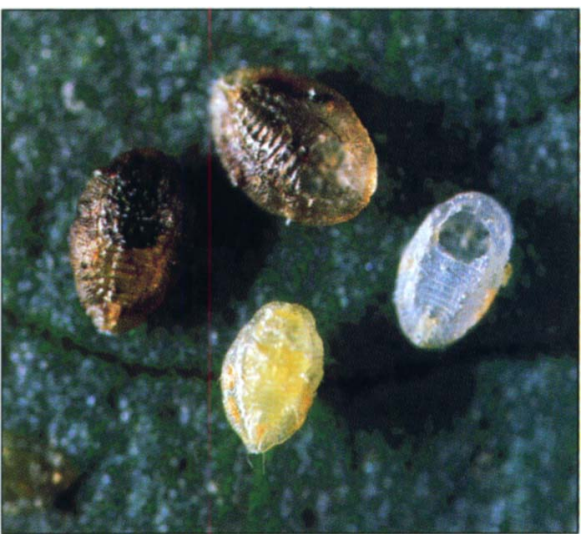
most pesticides. Melon growers apply pesticides two to five times per season. In 1996, Imperial County growers spent roughly $\$ 12$ million to protect 49,442 acres of melons from silverleaf whiteflies.

UC scientists and state Department of Food and Agriculture (CDFA) scientists are cooperating in battling the expensive pest. UC's Summers is tracking the movements of silverleaf whitefly, while CDFA entomologist Charles Pickett is researching the prospects for biological control of the pest.

Summers, who is based at the UC

Scientists are testing the effectiveness of parasitoids for silverleaf whitefly control. Top, an Encarsia pergandiella lays its egg in a silverleaf whitefly nymph. Above, whitefly nymphs parasitized by E. pergandiella and Encarsia luteola. silverleaf whitefly adults into citrus in eastern Tulare County. In a survey conducted in September 1996, Summers found populations of silverleaf whitefly nymphs were high enough to leave large quantities of honeydew on the fruit.

"Silverleaf whitefly has become adapted to citrus over the past 3 to 4 years and is currently a year-round resident," he says.

CDFA entomologist Charles Pickett is investigating the role that parasitoids may play in controlling silverleaf whitefly. The USDA collected and screened parasitoids from different parts of the world. Pickett has released large numbers of these exotic parasitoids into citrus and other crops where silverleaf whitefly overwinters in the Imperial and San Joaquin valleys. He hopes to increase the number of the whitefly's natural enemies. "We have one native species of Eretmocerus eremicus and two species of Encarsia that didn't do much," he explains. "We're trying to increase their diversity. The different parasites may perform better in some crops than others because every type of plant represents a different habitat.

"We have three or four that look promising; they've persisted over a year, maybe 2 years in some locations," Pickett says. The new species of Eretmocerus collected in Spain, Pakistan and the United Arab Emirates are in the process of being described so they don't have official names.

"Our long-term goal is to reduce the whitefly in noncrop situations - urban areas and along margins and perimeters of fields. If we can do that, it may reduce regional populations and the frequency of pesticide applications may drop."

Applying parasitoids instead of pesticides to fields may be another alternative for growers. Pickett has also experimented with biocontrol by augmenting with parasitoids mass-reared at CDFA's biological control greenhouse facility in Sacramento and with the USDA-APHIS in 
Brawley. Last year and this the augmentative trials are being done on a large scale in the Imperial Valley. He is placing the parasites in commercial organic fields and comparing their control with conventional fields that use the pesticide imidacloprid.

"We are using an Eretmocerus collected from the United Arab Emirates for the augmentative studies. About 3 years of data show that you can get comparable control, and the cost is comparable in spring melons," he says.

Pickett is also using transplants as a vehicle for getting the parasites into the field. Transplants are inoculated with whiteflies, then parasites just prior to planting in the field so $95 \%$ or more of the whiteflies will be parasitized. "We think this may be a more efficient means of releasing the parasites, reducing the overall cost," he says. - Editor

\section{Scientists see spike in Africanized bee numbers}

A fter an unexpectedly slow spread since their 1994 arrival in the state, Africanized honey bees (AHB) may have quintupled their numbers recently in southeastern California.

UC Davis graduate student David Nielsen and UC Davis entomologist Robert Page have been charting the AHB's progress since 1995. They report that in 1997,7\% of 502 captured bees were Africanized. That figure is up almost five-fold from 1996, when $1.5 \%$ of foraging bees captured were Africanized.

"These were all foraging bees, separated from their colonies," Nielsen notes, "so each one could represent a separate colony."

The scientists sampled in a core area bounded by Palm Springs on the west, Highway 10 on the north, The Colorado River (Arizona border) on the east and the Mexican border on the south. In 1995, the researchers brought back 75 bees and none were AHB. In 1996, they brought back 196 bees and 3 were AHB; in 1997, they brought back 502 bees and 34 were AHB, Nielsen said. After capturing foraging bees in sweep nets, the scientists used UC Davis-developed DNA tests to rapidly identify AHBs, which appear identical to European honey bees.

Nielsen believes the AHB's slow initial progress could be related to several factors, one being the varroa mite, which has parasitized honey bee colonies statewide and wiped out $85 \%$ of wild bees (see page 9 ).

Varroa mites can kill off a bee colony in 6 to 18 months. The external mites lay eggs on the bee larvae. The parasites suck fluids and nutrients out of the bee during its larval and pupal stages. A bee can survive one mite, but as more parasites feed on the developing bee, the emerging adult bee may become deformed and may not be a productive member of the colony. (Another theory, not widely held, is that the mite infects the bee with a pathogen that disables the bee.) Tracheal mites, which invade bees' trachea, also contribute to the bee decline, but because they are internal they are harder to detect. Colony losses due to tracheal mites have been extensive, but it appears that colonies have varying levels of natural resistance to these mites, so they may not pose as great of an obstacle to the Africanized bees or to the beekeeping industry as varroa.

There is some evidence that Africanized bees possess some resistance to varroa mites. "We know that their populations are stable in many areas and increasing within the state," Nielsen says. "On the other hand, our feral honey bee population is down to $10 \%$ or possibly less of its original strength. It's possible that the only feral bees we see now are mainly escapees from commercial hives."

Commercial bees are surviving because beekeepers treat for varroa with fluvalinate mite strips. The future of these is clouded because there is also evidence, primarily anecdotal, that varroa mites are developing resistance to this miticide.

"I think the Africanized bee's slow advancement in the U.S. is also a function of climate," Nielsen says. "The AHB's current distribution in the U.S. includes strictly the dry, arid climates of the Southwest, but bees in these regions require urban or irrigated areas to obtain enough food and a constant supply of water to flourish. They currently have survival problems in those areas with high humidity or harsh winters."

AHB has been in Texas for a long time, but has not moved to the east - possibly because

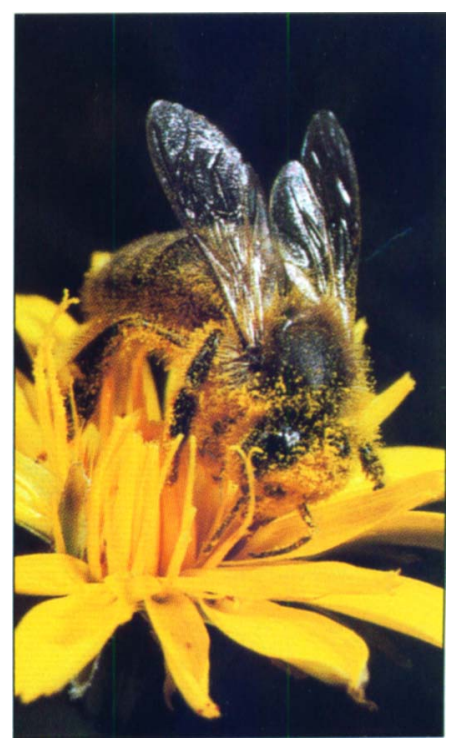

Feral honey bees, which have been nearly wiped out by the varroa mite, are one of a number of natural pollinator species on the decline. 